\title{
Order of recall in short-term memory
}

HARVEY A. TAUB, ${ }^{1}$ and RICHARD A. MONTY, Syracuse VA Hospital, Syracuse, N.Y., and U.S. Army Human Engineering Laboratories, Aberdeen Proving Ground, Maryland

Short-term recall of letter sequences, color-coded into two halves, was measured as a function of color presented first, alphabet half presented first, order of report, and blocks of trials. Analysis of the first half of Ss' reports suggested that reports which reversed the colored halves were superior to an ordered report of the colors except in trial block one when the letters presented first in a sequence were from the first half of the alphabet. Trends from the second half of a report were in the direction of more accurate recall with reversed as compared to ordered reports.

In a recent study by Taub (1968), it was noted that when letter sequences were color-coded into two halves, recall was most accurate when the order of report of coded halves was the reverse of the order of presentation. That is, letters presented in the first half of a sequence were recalled best if they were the second half of $S$ 's report, while letters presented in the second half of a sequence were recalled best if they were the first half of S's report. To explain the findings for the first half of S's report, it was assumed that immediate recall of the letters presented second (reversed report) would be relatively free from interference and thus more accurate than the deferred report of the letters from the first half of the sequence (ordered report). Further, to explain the finding for the second half of S's report it was assumed that interference produced by the first half of a report would have less of an effect upon letters presented first, a set which could be rehearsed a number of times before reporting (reversed report), than upon letters presented second, a set with little chance for repeated rehearsals (ordered report).

Although these findings of Taub (1968) were generally consistent over trials and age groups, the nature of the experimental design did not allow for the separation and analysis of possible pertinent task variables such as effect of color, effect of letters of the alphabet, and their interactions with order of report. The present experiment was designed to investigate these factors.

$$
\text { METHOD }
$$

Forty-eight introductory psychology students at Syracuse University served as $S s$ in a task similar to that described by Taub (1968). Briefly, each S was seated in front of a metal cabinet which contained a yellow pilot light to indicate the intertrial interval and a Grason-Stadler Co. multiple stimulus projector unit capable of displaying any of 12 different letters, one at a time, onto the center of a $1-1 / 8$ in. diameter frosted glass surface. All the letters were black against either a red or green background.

Each stimulus sequence consisted of eight letters, the first four of which were presented on one of the colored backgrounds, and the second four of which were presented on the other colored background. Further, all four letters within a color were drawn from one half of the alphabet, while the letters of the other color were drawn from the other half of the alphabet.

The letters from the first half of the alphabet available for use were $A, C, E, H, K$, and $L$, while $N, P, S, U, X$, and $Z$ were the letters from the second half of the alphabet. These letters were used to generate a total of 12 stimulus sequences with the restrictions that (a) none of the sequences spell real words, (b) each of the 12 letters appear approximately the same number of times over the trials, and (c) none of the letters appear more than once in any particular sequence.

The Ss' answers were written in booklets which provided a separate page for each presentation of a sequence (trial). Each page contained spaces arranged into two groups of four lines, each labeled as red or green with the first group of lines always corresponding to the color Ss were to report first.

Three female and three male Ss were assigned to each of eight experimental groups derived from a 2 by 2 by 2 factorial combination of two stimulus variables and one response variable. The stimulus variables, defined by the color of letters presented first and by the half of the alphabet from which they were drawn, are designated as Color and Alphabet. The response variable, designated as Order of Report, was defined by the order in which Ss reported the stimuli. That is, Ss were instructed to watch a sequence of four red and four green letters and then to report as many letters as they could remember. A color to report first was assigned and had to be reported in order before the letters of the second color. For half the Ss the color to be reported first was also presented first (Ordered Report), while for the rest, the color to be reported first was presented second (Reversed Report).

It was further stressed that Ss should always attempt to duplicate the order of presentation of letters within a given color grouping and that appropriate blank spaces should be left on the answer sheets if a letter could not be recalled. The stimuli were presented at the rate of one letter per second, with an off-time (interstimulus interval) of $.05 \mathrm{sec}$. The intertrial interval was S-paced to allow for sufficient writing time.

\section{RESULTS AND DISCUSSION}

The criterion of performance was the number of letters correctly recalled in order within each color group. Two analyses of variance were performed, one on the letters reported first and one on the letters reported second. In each analysis, Color, Alphabet, and Order of Report were included as between-Ss variables. Further, in order to assess the effect of practice, recall scores were summed to give two blocks of six trials which were included as a within-Ss variable.

The only main effect which produced significant differences in the analysis of the letters reported first was Order of Report $(F(1,40)=7.45, p<.01)$ with the data suggesting that reversed reports led to better recall than did ordered reports. Color did not produce significant differences either alone or in combination with any of the other variables. Neither Alphabet nor Blocks of Trials affected overall performance, but both contributed to the significant interactions of Alphabet by Blocks of Trials $(F(1,40)=4.52$, $p<.05)$, Order of Report by Blocks of Trials $(F(1,40)=8.14$, $\mathrm{p}<.01$ ), and Alphabet by Order of Report by Blocks of Trials $(\mathrm{F}(1,40)=15.52, \mathrm{p}<.01)$. This latter interaction, illustrated in Fig. 1, indicates that in general, Reversed Reports were superior to Ordered Reports except in Block 1 when the letters presented first in a sequence were from the first half of the alphabet. These findings agree with the previous results of Taub (1968) for letter sequences and of Posner (1964) for digit sequences. However, the significant interaction of Alphabet by Order of Report by Blocks of Trials further suggests that although reversed reports may be the optimum mode of responding, additional factors such as choice of letters for each half of the sequence might serve to enhance or inhibit the efficacy using this mode. Examination of

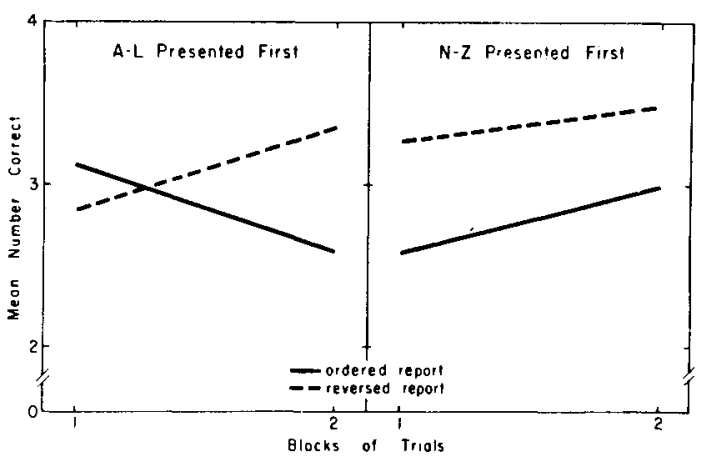

Fig. 1. Mean number of letters correctly reported in the first half of Ss' reports as a function of blocks of trials, alphabet half presented first, and onder of report. 
the present sequences indicates that the letters from the first half of the alphabet have a greater frequency of use in the English language and may have been combined to have greater meaning than the letters from the second half. This suggests that the more meaningful the first half of the sequence, the more difficult might be the reversal. Further, it is suggested that the decline in performance over blocks for the ordered reports when the first half of the alphabet was presented first may similarly be explained by the choice of stimuli with those in Block 1 being more meaningful than those in Block 2.

The analysis for the letters reported second indicates that the only significant effects were Trials $(F(1,40)=6.70, p<.05)$ and Alphabet by Trials $(F(1,40)=9.26, p<.01)$ with the data suggesting a greater improvement over the blocks of trials for the letters from the second half of the alphabet as compared to the first half. The lack of a significant effect for Order of Report was contrary to the expectation derived from Taub (1968). However, the trends were in the direction of more accurate recall with the reversed as compared to the ordered reports and suggest that the lack of significant differences was due to relatively high variability with this measure.

\section{REFERENCES}

POSNER, M. I. Rate of presentation and order of recall in immediate memory. British Journal of Psychology, 1964, 55, 303.306.

TAUB, H. A. Age differences in memory as a function of rate of presentation, order of report, and stimulus organization. Journal of Gerontology, 1968, $23,159-164$.

\section{NOTE}

1. Also affiliated with the State University of New York, Upstate Medical Center, Syracuse, New York. 